\title{
Leibniz's Monadological Positive Aesthetics
}

\author{
Pauline Phemister and Lloyd Strickland
}

\begin{abstract}
One of the most intriguing - and arguably counter-intuitive doctrines defended by environmental philosophers is that of positive aesthetics, the thesis that all of nature is beautiful. The doctrine has attained philosophical respectability only comparatively recently, thanks in no small part to the work of Allen Carlson, one of its foremost defenders. In this paper we argue that the doctrine can be found much earlier in the work of Gottfried Wilhelm Leibniz who devised and defended a version of positive aesthetics (avant la lettre) in the early modern period, grounded in a conception of the world as a world of monads, each of which individually fulfils the rationalist aesthetic criteria of multiplicity-in-unity and that taken together ensure that the world as a whole is a harmoniously ordered system of multiple and diverse individuals, whose intelligible order and variety is made known to us through natural scientific endeavour. In showing this, we advance two further theses: first, that Leibniz's version of positive aesthetics displays more philosophical virtue than Carlson's, for whereas Carlson's doctrine is vague and admits of exceptions, Leibniz's is clear and allencompassing. And secondly, that Leibniz's version of positive aesthetics has the resources to overcome a difficulty inherent in the exclusively science-based justification that Carlson offers.
\end{abstract}




\section{Introduction}

One of the most intriguing - and arguably counter-intuitive doctrines defended by environmental philosophers is that of positive aesthetics, the thesis that all of nature is beautiful. A perusal of the literature on the topic would lead one to suppose that while the belief that all nature is beautiful has been held by a number of artists and naturalists over the last two centuries, ${ }^{1}$ it has attained philosophical respectability only comparatively recently, thanks in no small part to the work of Allen Carlson, one of its foremost defenders. In this paper we shall show that such a picture is inadequate, inasmuch as it says nothing about the thought of Gottfried Wilhelm Leibniz, who devised and defended a version of positive aesthetics (avant la lettre) in the early modern period, grounded in a conception of the world as a world of monads, each of which individually fulfils the rationalist aesthetic criteria of multiplicity-in-unity and that taken together ensure that the world as a whole is a harmoniously ordered system of multiple and diverse individuals, whose intelligible order and variety is made known to us through natural scientific endeavour. In showing this, we advance two further theses: first, that Leibniz's version of positive aesthetics displays more philosophical virtue than Carlson's, for whereas Carlson's doctrine is vague and admits of exceptions, Leibniz's is clear and all-encompassing. And second, that Leibniz's version of positive aesthetics has the resources to overcome the difficulty inherent in the science-based justification that Carlson offers. To show this, we shall first outline Carlson's doctrine of positive aesthetics, and then turn our attention to Leibniz.

\section{Carlson's Positive Aesthetics}

In Aesthetics and the Environment, Allen Carlson defines positive aesthetics as the 'initially implausible' view that 'all the natural world is beautiful' and that 'the natural environment, insofar as it is 1 See Carlson 2000: 73-4 for examples. 
untouched by humans, has mainly positive aesthetic qualities' (Carlson 2000: 72). ${ }^{2}$ We might wonder - as indeed have others, such as Malcolm Budd - whether Carlson is here thinking of nature as whole, or the biosphere, ecosystems, species, individual (natural) things, or individual (natural) events. ${ }^{3}$ While Carlson doesn't specify, the way in which he seeks to justify positive aesthetics affords us a clue. He argues that in our appreciation of nature, we should adopt what he calls the 'natural environment model', according to which 'we must appreciate nature... in light of knowledge provided by the natural sciences, especially the environmental sciences such as geology, biology and ecology' (Carlson 2000: 6). More specifically, we should appreciate natural things under their correct categories, which are the categories that are discovered by naturalists. So for example, if we are appreciating a whale, we should do so under the category of 'mammal' rather than 'fish' or 'bird' or 'marsupial' etc. (Carlson 2000: 63ff). This enables us to appreciate it as what it actually is, which in turn enables us to have a richer, deeper appreciation of that thing. Unfortunately Carlson's insistence on our appreciating natural things under their correct categories does not

2 Originally published as Carlson 1984. As we shall see over the course of this paper, Leibniz's belief that the whole of nature is beautiful differs in various ways from the position that Carlson adopts. But one difference is worth noting now, which is this: Leibniz makes a distinction between the living machines of nature created by God and the artificial machines constructed by humans. The former have infinitely many enfolded parts; the latter have only a finite number of parts (New System: GP IV 482; L 456). The organic bodies of human beings are living machines and as such are just as much a part of nature as any other living body. Therefore to consider nature as beautiful only 'insofar as it is untouched by humans' is to separate the natural from the human in a way that Leibniz would not endorse.

3 See Budd 2002: 97. Needless to say, there is a rich literature on positive aesthetics, and in it one can find various other objections to the doctrine, or at any rate to versions thereof. It is beyond the scope of this paper to offer a detailed examination of this literature, and the objections found therein, and we thus leave it to the reader to assess how well Leibniz's version of positive aesthetics fares against objections found (for example) in Fisher 2001: 271-3 and Brady 2010. It should be noted, however, that many objections to positive aesthetics are aimed at one specific version of the doctrine. For example, the objection that it is highly implausible to suppose that all parts and elements of nature are equally beautiful (articulated for example in Budd 2002: 127, and Fisher 2001: 272) has force only against versions of positive aesthetics that make such a claim. 
enable us to determine precisely what he means when he talks of all nature having only positive aesthetic qualities, though it does allow us to make an educated guess. Certainly Carlson's choice of illustration for the doctrine (individual whales) suggests he thinks it applies to individual natural things (e.g. individual whales). However, we should here note Carlson's concession that some natural things are not aesthetically good. When faced with the objection that "grossly malformed living things will remain grotesque no matter how comprehensible science renders their malformation' (Budd 2002: 102, cf. 126), Carlson conceded that grossly malformed living things are exceptions to his view on positive aesthetics (Carlson 2002: 234n36). In another text, he admitted that 'damaged, diseased, and malformed living things' are all exceptions (Parsons \& Carlson 2008: 136). ${ }^{4}$ Clearly, then, Carlson sees positive aesthetics applying to individual natural things, but not to all of them, and not in all of their states. We might reasonably suppose that he would take it to apply to individual natural events as well, but it is less clear that he would also apply it to nature as whole, the biosphere, ecosystems, or species, given that these do not, according to conventional wisdom, fall under the senses because of their vastness or abstractness. But there is an element of conjecture here, because ultimately Carlson leaves the parameters of his version of positive aesthetics rather vague.

In any case, even if Carlson is unclear about what exactly falls under his version of positive aesthetics, he is clear about how it is to be grounded, insisting that scientific study of the natural world is the most effective route to the discovery of the positive aesthetic qualities that nature possesses in itself:

4 In this book, the authors advance an aesthetics of nature that emphasises the functional values that individuals possess in relation to each other and their environments. Although Leibniz's metaphysical views are highly relevant to this approach, it would take us too far from the topic of this paper to explore them here. 
When nature is aesthetically appreciated in virtue of the natural and environmental sciences, positive aesthetic appreciation is singularly appropriate, for, on the one hand, pristine nature - nature in its natural state - is an aesthetic ideal and, on the other, as science increasingly finds, or at least appears to find, unity, order, and harmony in nature, nature itself, when appreciated in light of such knowledge, appears more fully beautiful. (Carlson 2000: 12)

Insofar as scientific investigation of nature uncovers the aesthetic qualities that the natural world possesses in itself, it also serves as justification of a positive aesthetics of nature. The aim of the sciences is the intelligible explanation of phenomena. And in this endeavour the natural sciences seek to explain natural phenomena in terms of 'order, harmony, balance, tension, resolution, and so forth' (Carlson 2000: 93). These, as Carlson explains, are precisely the qualities that we find aesthetically pleasing:

these qualities that make the world seem comprehensible to us are also those that we find aesthetically good. Thus, when we experience them in the natural world or experience the natural world in terms of them, we find it aesthetically good. This is not surprising, for qualities such as order, regularity, harmony, balance, tension, and resolution are the kinds of qualities that we find aesthetically good in art. (Carlson 2000: 93)

Carlson does not speculate as to why it is that the criteria we apply in the sciences are the same criteria against which we judge the aesthetic qualities of works of art (ibid.). However, what is important in respect of a positive aesthetics of nature is that the scientific criteria lead to the discovery of truths about the natural world. It is 
not just that scientific studies are guided by the desire to make the natural world intelligible to us in terms of order, harmony, balance and the like, but also that in doing so, science discovers that the natural world is a world in which these aesthetically appealing qualities really are present. The natural sciences, he contends, do not impose these qualities on the environment. Rather, scientific investigation brings to light what is already there. In this way, the sciences reveal that nature itself is aesthetically good. In Carlson's own words,

these categories not only make the natural world appear aesthetically good, but in virtue of being correct determine that it is aesthetically good (Carlson 2000: 94).

The more that the sciences succeed in making intelligible the natural world as a world that is ordered, regular, harmonious and balanced, the more that world is found to be not only intelligible, but also aesthetically pleasing: 'the development of science and its continual self-revision ... constitutes a movement that puts the natural world in an increasingly favorable aesthetic light' (Carlson 2000: 94-95).

Furthermore, Carlson argues that the sciences provide the only viable justification for positive aesthetics. Of particular relevance to our purposes here is Carlson's rejection of theological justification as unsatisfactory. As Carlson sees it, a theological justification for positive aesthetics would be founded upon the belief that, having been designed and created by a perfect God, the world too would be perfect and, as such, all its aesthetic qualities would be positive qualities. While Carlson acknowledges that such an appeal to divine perfection would appear to justify the doctrine of positive aesthetics, he goes on to identify three 'puzzles' connected with it (Carlson 2000: 82). First, insofar as the justification is unavailable to atheists, 
it suggests, although it does not necessitate, the somewhat counterintuitive notion that atheists and theists appreciate nature in radically different ways. Second, traditional appeals to the perfection of the world give rise to the 'problem of evil', which theists usually tackle not by denying the existence of evil, but by constructing a theodicy that seeks to explain why God would permit evil to exist in the world. Yet in the analogous 'problem of ugliness', which would aim to reconcile God's existence with that of ugliness in the natural world, theists seeking to justify positive aesthetics through theology would be offering a decidedly non-analogous kind of solution, in that they would be simply denying the existence of ugliness, rather than attempting to create an aesthetic theodicy. Carlson considers this incongruous, arguing that the tradition of developing theodicies to tackle the problem of evil suggests that the theist should develop an aesthetic theodicy for the problem of ugliness rather than just denying the existence of ugliness. ${ }^{5}$ Third, and finally, Carlson points to the paucity of historical evidence of Christian thought promoting the appreciation of nature. On the contrary, he insists, Christianity has 'traditionally viewed wild nature as something to be confronted, dominated, and domesticated by human beings for their purposes' (Carlson 2000: 83) and that, at least in the West, 'Christianity and the aesthetic appreciation of nature have been opposing forces to an extent that the latter could grow only as the former went into decline' (Carlson 2000: 84).

In our view, Carlson's concerns about the theological justification of positive aesthetic are not warranted. For instance, his first point that the theological justification implies that theists and atheists appreciate nature differently - is not necessarily problematic. The difference could simply be acknowledged and accepted or absorbed within a wider conception of the role of theistic and atheistic

5 Although he does not put it quite like this, Carlson's point seems to be that analogous problems should admit of analogous solutions. 
appreciations of nature. ${ }^{6}$ Regarding the second objection, Carlson's suggestion that because theists have engaged in theodicy to resolve the problem of evil they should likewise engage in aesthetic theodicy to resolve the problem of ugliness (rather than simply denying ugliness), is clearly under-motivated. There is no compelling reason why the two problems cannot be resolved in different ways. But if one insists that they have to be, one need only look at the work of Leibniz to see how both problems can be resolved in analogous ways. For Leibniz acknowledged evil in the parts while insisting that such evil is a necessary feature of a perfect whole and disappears in relation to it; ${ }^{7}$ similarly he proposes (as we shall see) that negative aesthetic qualities in nature are either merely apparent or real only when the individual parts of nature are considered in isolation from the whole. Leibniz thus offers a traditional theodicy, and a cognate aesthetic theodicy. Finally, to Carlson's third objection, the historical fact of Christianity's appalling track record is not in dispute: for centuries, the basic thrust of Christianity has been disadvantageous to the non-human world. However, historical record is not particularly relevant to the question whether it is possible to justify positive aesthetics of nature on theological grounds. The fact that Christians have historically failed to acknowledge the goodness and beauty of the natural world is not a declaration of the inevitability of Christian antipathy towards nature. The future need not always resemble the past. In any case, it is far from clear that the failure is as great as Carlson makes it out to be: the historical record affords us numerous examples of Christian thinkers who have readily made positive aesthetic judgements about nature, such as Thomas Burnet, John Ray, and

6 The conclusions to be drawn later in this paper would support this second suggestion.

7 See for example, Leibniz's Remarks on the three volumes entitled Characteristics of Men, Manners, Opinions, Times, ... 1711: GP III 429; L 633. See also On the Ultimate Origination of Things: GP VII 306-308; AG 153-154. 
George Berkeley. ${ }^{8}$ And today, positive, nature-affirming interpretations of Scripture are available as part of a contemporary theological drive towards a re-evaluation of the relation of God and world. Irrespective of how we view the historical record, in recent times, writings such as those of prominent theologian Jürgen Moltmann stand testimony to the power of Christian thought to support human appreciation and concern for Creation (Moltmann 1985).

All the same, even if the objections to the theological defence of positive aesthetics obtain and theological appeals to God's perfection and creativity are found insufficient to ground a positive aesthetics of nature, this does not mean that theological considerations should be rejected tout court, for, as will be argued below, they do have important justificatory value.

We begin however, with a defence of a positive aesthetics interpretation of Leibniz's account of the beauty of the natural world, before going on to explore the role of the natural sciences in bringing the objective beauty of nature into view. We will find that the natural sciences, while a necessary staging-post, are incapable of providing a full justification of positive aesthetics. We will also discover that, for Leibniz, not only do the sciences themselves require theological grounding, but also that a theological justification of natural beauty uncovers a world the extent of whose beauty is even greater than that which the natural sciences can reveal. In conclusion it will be suggested that the most solid defence of positive aesthetics lies in the combination of a scientific justification underpinned and extended by a rationalist theology.

8 See Burnet 1684: 109; Ray 1691: 150ff; Berkeley 2008: 192. And Leibniz is of course another who makes positive aesthetic judgements about nature, as we shall show. 
Only when the sciences and theology work together does positive aesthetics come to rest on a sure foundation.

\section{The positive aesthetics of Leibniz}

Following Ernst Cassirer (Cassirer 2009 [1951]: 34), recent accounts of eighteenth-century rationalist aesthetics have acknowledged the undoubted immense debt to Leibniz owed by his immediate successors, Christian Wolff and Alexander Baumgarten. For instance, Frederick Beiser (Beiser 2009) and Paul Guyer (Guyer 2014: 49-52) have drawn our attention to the influence of Leibniz's thought on the eighteenth century rational aesthetics that stem from Wolff and Baumgarten. The genealogy is instructive and persuasive. As Beiser's penetrating and lucid account shows, Leibniz's Principle of Sufficient Reason provided the basis for an aesthetics that maintains that the predication of beauty must be grounded upon intelligible principles of harmony, order and perfection, understood in terms of 'unity-in-variety' (Beiser 2009: 4-8). Nevertheless, there are dangers and pitfalls that must be avoided when we read Leibniz backwards through the prism of the tradition of rationalist aesthetics that his thought inspired. The aesthetics of Wolff and Baumgarten combine both subjective and objective elements. For Wolff, beauty is subjective insofar as it exists as a feeling of pleasure: if there is no feeling of pleasure, there is no beauty. But insofar as this feeling of pleasure is a response to an actual perfection in the object itself, beauty is also objective. The subjective and objective elements are combined, Beiser holds, in Wolff's definition of beauty as the 'observability of perfection': the definition 'neatly joins both these elements together, for it means that beauty is neither perfection nor pleasure alone but both: the pleasure from observing perfection.' (Beiser 2009: 63). On Beiser's reading, Baumgarten adopts the same stance: beauty is objective insofar as it is grounded in the 
actual perfection of the object and it is subjective insofar as beauty must be sensed and cognized. ${ }^{9}$

Following Wolff, Baumgarten's central thesis is that beauty consists in the intuition of perfection. ... Such a thesis attempts to explain both the subjective and objective aspects of beauty. In making perfection essential to beauty, it makes beauty partially objective. If there were no variety-in-unity in the object, there would be no beauty. But in making intuition also crucial to beauty, it also makes beauty subjective. If there were no sensible perception of perfection, there also would be no beauty. (Beiser 2009: 145)

Looking back to Leibniz from the perspective offered by Wolff and Baumgarten, it is natural to read Leibniz in the same way. Accordingly, Beiser states that for Leibniz, 'beauty is both a subjective and objective quality' (Beiser 2009: 36). As evidence, he cites Leibniz's well-known definition of beauty as 'that, the contemplation of which is pleasant' (Elements of Natural Law: A VI i 464: L 137). On Beiser's reading, 'contemplation' introduces a subjective element into Leibniz's account of beauty that is additional to the objective element already present insofar as Leibniz regards pleasure as a feeling that arises when perfections that exist objectively in the things are perceived (Beiser 2009: 35).

However, when we read Leibniz on his own terms, freed from the legacy of Wolff and Baumgarten's interpretations, the case for reading Leibniz's definition as indicative of the subjectivity of beauty is significantly weakened. Reading Leibniz not through his enlightenment reception, but rather through the lens of his classical heritage brings Leibniz's opinion that beauty is an objective quality

9 For Baumgarten, aesthetics is the 'science of sensitive cognition' (Aesthetics, $\S 1)$. See Beiser 2009: 119. 
into sharper focus. The general consensus prior to the eighteenth century was that the objective beauty of things was found in the unified order and proportion of their parts, ${ }^{10}$ and therefore does not depend upon its also being subjectively perceived. Under this light, Leibniz's claim that it is pleasing to contemplate beautiful things no more suggests that things are beautiful only when we actually contemplate them than it suggests that the pleasure we get from contemplating or discovering scientific truths suggests that they are true only when we are actually contemplating them. When introducing his definition of beauty as 'that, the contemplation of which is pleasant', he prefaced his remark with the observation that 'We seek beautiful things because they are pleasant' (Elements of Natural Law: A VI i 464: L 137). This strongly suggests that beauty exists independently of our perception or contemplation of it and that the contemplation of beautiful things is pleasing to us in consequence of their beauty, not a requisite for their beauty. They would be beautiful even were there no one to contemplate them. The same is true of God's perception. God knows the beauty of things, but they are beautiful in themselves, not beautiful because God knows them. ${ }^{11}$

Other of Leibniz's remarks on the beauty of things confirm what is here implied, namely that beauty is wholly objective, and not reliant in any way on subjective perception or contemplation. ${ }^{12}$ For example, in a piece on true piety and the love of God, Leibniz writes that 'we consider a painting excellent not because of some usefulness to us, but because of its own beauty' (The elements of

10 Augustine, for instance, endorsed the by then popular Aristotelian view that conceives beauty in terms of the orderly arrangement of parts. See Aristotle Poetics 1450a36-37: Barnes 1984: II 2322; Augustine, De ordine II.15.42: Borruso 2007: 105-107.

11 See for example Rationale Fidei Catholicae, A VI iv, 2320; LGR 76-7.

12 Obviously, of course, subjective perception or contemplation is still necessary if this objective beauty is to be perceived and appreciated. 
true piety, or, on the love of God over everything: A VI iv 1357: SLT 189, my emphasis), while shortly after in the same piece he repeats his observation that 'The beautiful is that, the contemplation of which is pleasant' (A VI iv 1358: SLT 190). Were this remark to be read as laying claim to the subjectivity of beauty, it would undermine Leibniz's earlier comment in the same piece on the objective beauty of the painting. Leibniz also holds that God Himself is beautiful - 'nothing is happier than God and also nothing can be understood as being more beautiful or more worthy of happiness' (Preface to the Diplomatic Code of People's Rights: GP III 387: SLT 150). God's beauty depends neither on our, nor on God's, contemplation of it. Finally, we may note that it is not only individual created things and God that are objectively beautiful. Leibniz asserts that the world as a whole has an objective beauty that, far from being even in part subjectively dependent upon our contemplation or pleasure, already exists, ready for us to discover provided we pay sufficient attention informed by the truths of mathematics:

we must acknowledge that it is important that one have some general insights on mathematics, not as craftsmen have for the accuracy of their works, but because of the openings that one finds in it for elevating the mind to thoughts that are beautiful and sound in equal measure. For without that the items of human knowledge are only vague and superficial. This is clearly seen with regard to the system of the visible universe, about which the previous century and ours have made wonderful discoveries, and what the ancients knew of it was mere juvenilia compared to what is known about it now. This system or structure of the visible world is of an admirable beauty which gives true ideas of the grandeur and harmony of the universe ...

(Leibniz to Sophie, 23 October/2 November 1691: A I vii 49-50: LTS 91-92) 
Passages such as these portray Leibniz as an early exponent of a positive aesthetic of nature. First, he assumes that beautiful things are objectively beautiful. Their beauty does not depend upon being felt or contemplated. Beauty is a feature of things themselves, discoverable through close attention to the empirical detail, grounded in the cognitive truths of the mathematical sciences. Second, as we see from the passage just cited from Leibniz's correspondence with Sophie, Leibniz also views nature or the universe in a wholly positive light. Other passages are even more explicit about this; for example, Leibniz informs us that 'God created everything in accordance with the greatest harmony or beauty possible' (Aphorisms concerning happiness, wisdom, charity and justice: A VI iv 2799; LGR 138). Thus, in anticipation of rational aesthetics in the eighteenth century and Carlson's adoption of similar criteria for aesthetic goodness in our own, Leibniz held that the true perfection and beauty of the universe resides in its being a harmoniously ordered and infinitely varied plurality of individual living substances. Any ugly disorder we believe to occur in nature is more apparent than real. When we see such negative qualities in the context of the whole, the disorder vanishes:

the apparent disorders are only like certain chords in music which sound bad when one hears them by themselves, but which a skillful composer leaves in his work because by combining them with other chords they increase one's enjoyment, and render the whole harmony more beautiful. (Leibniz to Sophie Charlotte, 9/19 May 1697: GP VII 545: LTS 160)

Elsewhere, Leibniz explains that 'all the imperfections we think we find in the world only originate from our ignorance' and that we lack 'the right point of view to judge of the beauty of things' (to André 
Morell, 29 September 1698: A I xvi 162: SLT 197). We have relatively distinct perceptions of only a tiny fragment of this spatially and temporally infinite plenum of a universe. For the most part, our perceptions are confused: we do not clearly perceive the parts of an object, or of the universe, and so fail to appreciate fully and intellectually the perfect harmonious order of the whole. It is hardly surprising, therefore, that we fail to appreciate its beauty in all its finest glory (Leibniz to Sophie Charlotte, 9/19 May 1697: GP VII 545: LTS 160). Nevertheless, even when our perceptions are confused, we may still have a sense that 'There is something, I know not what, that pleases me in the matter', and this sense testifies to the fact that at the level of 'our feelings [Gemüth]' we have registered or perceived the presence of intrinsic, objective perfection and beauty (On Wisdom: GP VII 86: L 425-426).

\section{Leibniz and the sciences}

One might with reason expect Leibniz to justify his positive aesthetics theologically by simply appealing directly to God's goodness and perfection. After all, Leibniz does maintain that God freely chose to create this world rather than any other world because this world is the best of all possible worlds. Obviously, an omnipotent, omniscient and benevolent God, wisely guided by the principle of the best, will choose to create that world that is the most harmonious, most ordered, good and beautiful, in short, the world that is the most perfect. ${ }^{13}$

Surprisingly, however, Leibniz does not, at least in the first instance, justify the positive beauty and perfection of the world by appealing to God's perfection. On the contrary, we find him arguing in the

13 See Theodicy §416: G VI 364, where Leibniz envisions possible worlds being ranked in terms of beauty, and God choosing the most beautiful one, namely ours, the best of all possible worlds. 
opposite direction: the beauty and perfection that we find in the world leads us to knowledge of God. Leibniz declares that there are in fact two ways that lead to knowledge of God's beauty and perfections 'through his emanations':

namely in the knowledge of eternal truths, explaining the reasons in themselves, and in the knowledge of the harmony of the universe, by applying reasons to facts. That is to say, we must know the wonders of reason and the wonders of nature. (Happiness: Gr 580-81; SLT 168)

The 'wonders of reason and of eternal truths' concern the truths of arithmetic, geometry, justice and morals that the mind 'discovers in itself in the sciences of reasoning'. However, the 'wonders of corporeal nature', which include 'the system of the universe, the structure of the bodies of animals, the causes of the rainbow, of the magnet, of tidal ebb and flow, and a thousand other similar things' (Happiness: Gr 581; SLT 168), had been discovered only through natural scientific application of 'reasons to facts'. It was this methodology that had led to Nicolas Copernicus' revolutionising of our understanding of the heavens, Johannes Kepler's discovery of the elliptical paths of the planets and realisation of the role played by the moon in the turning of the tides, the painstaking uncovering of minute worlds by microscopists such as Antonie van Leeuwenhoek, William Harvey's discovery of the circulation of the blood, Descartes' and Newton's studies of the rainbow, and William Gilbert's theory of magnetism.

Although he does not coin the phrase, in Leibniz's acknowledgment of the value of the applied natural sciences in bringing to light the 'wonders of nature', we see him moving towards a justification of positive aesthetics that bears a remarkable affinity to Carlson's own justification by the natural sciences. From mathematical physics and 
astronomy to chemistry, anatomy, and physiology, the natural sciences were transforming early modern understanding of the natural world and humans' place within it. But more than this, they were discovering order, variety and harmony throughout all parts of the universe. And the more they discovered, the more the beauty of the universe came to light. In the words of Leibniz:

It is only in our time that we are beginning to recognize the secret of both the little and the great world, by the discovery, on the one hand, of the circulation of the blood in ourselves, and on the other hand (by means of telescopes) of the true movements of the heavenly bodies. If human beings continue to make progress as they have within the past hundred years, many things of wonderful beauty will be displayed by nature

(Thoughts on Van Helmont's doctrines, first half of October (?) 1696: A I xiii, 51; LTS 139)

Leibniz's stance is clearly in the spirit of Carlson's natural scientific defence of positive aesthetics. There are differences in their respective conceptions of the natural sciences: Leibniz's mathematically informed approach stands in contrast to the natural historical approach favoured by Carlson in which classification according to natural categories dominates. ${ }^{14}$ Nevertheless, whatever the actual methodology employed, both Leibniz and Carlson are convinced that natural scientific investigation is the means by which

14 We thank an anonymous referee for this point. We thank another anonymous referee for pointing out that there is a degree of subjectivity inherent in the human categorization of nature that creates a certain tension with the idea of objective beauty grounded in these categories. The idea is that the categories we employ in our understanding of nature are to some extent nominal or arbitrary. Carlson himself, however, considers the categories of nature as objectively true natural kinds, discovered rather than created by natural sciences (Carlson 2000: 90). The issue does not arise for Leibniz, for he locates the beauty of nature not in categories or species, but in its unique individual constituents that together form a similarly unique and beautiful whole. 
objective natural beauty, as intelligible order and harmony, is discovered and appreciated.

Leibniz himself, however, goes beyond this to claim that those 'many things of wonderful beauty' that we find in nature, 'give us yet more cause to esteem their creator, and to take pleasure in his acts' (Thoughts on Van Helmont's doctrines, first half of October(?) 1696: A I xiii, 51; LTS 139). The discovery of beauty in nature leads us to acknowledge not only the positive beauty of the natural world, but also the wisdom, perfection and beauty of the creator and of the individual perceivers of this beauty. As he remarked to Sophie Charlotte, the more we uncover the order and harmony in the natural world, the more we are convinced that

the universe is governed by a sovereign intelligence, in an order so perfect that, if one understood it in detail, one would not only believe but would even see that nothing better could be wished for. (Leibniz to Sophie Charlotte, 9/19 May 1697: GP VII 545; LTS 160). ${ }^{15}$

The natural sciences tell us how things work, but not why they work as they do. Laws and regularities are discovered, but the sciences do not and cannot explain why these ones obtain rather than others. The sciences reveal that the world is intelligible, but do not explain why it is intelligible. Nor indeed, can they offer any explanation as to why a world exists at all. In aesthetics, as the eighteenth century rationalist aestheticians had agreed, Leibniz's Principle of Sufficient Reason, rigorously applied, points to the need not only to declare

15 Indeed, Leibniz even saw in the beauty of the world an argument - albeit not a demonstrative one - for the existence of God, for he writes that 'from the beauty of things alone it is indeed very probable that the world was constructed by a most wise architect', that is, God (On freedom, fate and God's grace: A VI iv 1604; LGR 262). In one early writing, he even suggested that the world's beauty afforded an 'infinite probability, or moral certainty' that a mind - God's - was behind it (Sketch of Catholic Demonstrations: A VI i 494; LGR 22). 
that we find certain things beautiful, but also to justify the attribution by giving the reasons upon which the judgement is founded. In the natural sciences, the Principle of Sufficient Reason grounds the belief that all phenomena are explicable in terms of efficient causation, but it also shows up the limitations of such explanations and highlights the need to postulate an ultimate reason that lies beyond the range of the empirical sciences. Such an ultimate reason appeals to the considerations of goodness and perfection that entered into God's decision to create the best possible world. In this, it prioritises final causation over efficient causation: the laws of efficient causation that govern the collisions among bodies must, in the end, be explained by final causation's reference to the divine will to create that possible world that God understood to be the best (Principles of Nature and Grace, §§ 8-11: GP VI 6-2-603; AG 210-211). ${ }^{16}$

We must not distrust the pleasures that arise from intelligence or reasons, when we penetrate the reason of the reason of perfections, that is to say, when we see them follow from their source, which is the absolutely perfect being.

The perfect being is called God. He is the final reason of things, and the cause of causes. Being the sovereign wisdom and sovereign power, he has always chosen the best and always acts in an orderly way (Happiness: Gr 580; SLT 168)

The natural sciences provide us in the first instance with knowledge of the beauty of nature, but in doing so they also expose their own limitations. God is needed as the ultimate reason why the world exists and the reason why the best possible world exists. God chose to create this world rather than any other because he knew that this

16 ' $[T]$ he laws of motion cannot be explained through purely geometric principles or by imagination alone ... they originate in the wisdom of their Author or in the principle of greatest perfection, which has led to their choice.' (Tentamen Anagogicum: GP VII 271-272; L 478). 
world fulfilled the criteria of goodness, harmony, order, beauty and perfection, these being attributes that this world possesses objectively, i.e. in itself. We thus see that the Leibnizian theological justification of positive aesthetics works together with a scientific justification. First, examples of the beauty and perfection of the world are discovered by the natural sciences, but these in turn need to be explained by reference to decision of a perfect and rational God to create the best possible world, which in turn justifies the positive aesthetical claim about the whole of nature, including those parts that have not yet been uncovered through scientific investigation, and consequently of whose beauty we do not at present 'have the right point of view to judge' (to André Morell, 29 September 1698: A I xvi 162; SLT 197).

It is a bit like in astronomy, where the motion of the planets appears to be a pure confusion when one looks at it from the Earth, but if we were in the sun we would find before our very eyes this beautiful arrangement of the system which Copernicus has discovered by dint of reasoning. As the smallest bodies are, so to speak, small worlds full of marvellous creatures, we should not imagine that there are barren parts, absolutely speaking, even though they seem barren to us. (ibid.)

Indeed, as Leibniz here hints with his reference to the absence of 'barren parts' of nature, the perfection and beauty of God's creation extends far beyond that which can ever be made known to us through the empirical sciences alone. The sciences have made incredible advances in uncovering the wealth of variety and mechanical ordering among bodies. As such, however, they are concerned only with the physical aspects of living beings, including those 'marvellous creatures' in the seemingly 'barren parts' of nature to which Leibniz referred Morell. The physical sciences 
struggle to describe and explain the psychical aspects of these creatures: the inner, subjective experiences had by the monadic minds, souls or entelechies that Leibniz believed dominate and unify their organic bodies. ${ }^{17}$ In addition to the beautiful order and variety found in bodies, there is a beautiful order and variety to be found in minds, souls and entelechies whose perceptions 'cannot be explained mechanically' (Monadology §17: GP VI 609: M 17), but which instead must be explained in terms of the same kinds of reasons or final causes that inclined - but did not necessitate - God to create this world instead of any of the other possible worlds, namely the will, desire or appetite towards what is (or what appears to be) the best. (On the Ultimate Origination of Things: GP VII 302: AG 150. See also New Essays: A VI vi 178-179; RB 178-179).

\section{The best possible world}

Leibniz's vision of the best possible world describes a harmonious plenum of living beings, of perceiving souls or entelechies and their organic bodies, which bodies are themselves composed of other monads with organic bodies, ad infinitum. Underpinning the phenomenal world of physical nature is a metaphysical world of monadic unities. The opening sections of Leibniz's Monadology demonstrate the logical necessity of the indivisible, unified and unifying monads as the foundational requisites of the physical world of divided aggregate bodies:

1. The monad, about which we shall speak here, is nothing other than a simple substance which enters into compounds, 'simple' meaning 'without parts'. (Theodicy, preliminary discourse §10).

17 According to Leibniz, bodies are either corporeal substances, that is, living bodies endowed with dominant minds, souls or entelechies or aggregates of corporeal substances (to Bierling, 12 August 1711: GP VII 501). 
2. And there must be simple substances, because there are compounds; for the compound is nothing but an accumulation or aggregate of simples.

3. Now where there are no parts, neither extension, nor shape, nor divisibility is possible. And these monads are the true atoms of nature and, in a word, the elements of things.

(Monadology §§ 1-3: GP VI 607; M 14)

No created monad is ever separated from its organic body. Each is dominant over a constantly changing aggregate of substances (and aggregate of subordinate monads with their own organic bodies), forming with them an animal-like, living unity, a corporeal substance (Phemister 2005: chapters 1-3). Perceiving as a unified whole the effects of other substances on its own body, each monad constitutes a unique perspective on the world. ${ }^{18}$ Through the organs of its own body, every monadic soul perceives the entire world from its own 'point of view', reflecting like a mirror the harmoniously ordered and varied whole: 'souls in general are living mirrors or images of the universe of created things' (Monadology §83: GP VI 621; M 31). Every monad is thus a unique representation of the infinitely varied multiplicity of monads with bodies (i.e. living creatures) that make up this world.

Crucially, this means that every monad is itself a thing of great beauty. Every monad is a 'unity-in-variety' and each of its passing perceptions is also a 'unity-in-variety', being a unified representation - from its own unique point of view - of the current state of the

18 Each monadic soul or entelechy perceives the effects of the external world on each of its body's parts, holding the entire causal sequence leading up to present states of each part in a single indivisible perception and making possible the corporeal substance's role as itself a cause of future effects on others (Phemister 2015: 137-140). 
whole of this beautifully varied and perfectly ordered harmonious universe. As Leibniz conceives the matter, when we perceive perfections, the images of those perfections in our minds are repetitions of the perfections present in what is perceived and thereby serve to perfect the mind itself. In a discussion of pleasure in On Wisdom, he explains

Pleasure is the feeling of a perfection or an excellence, whether in ourselves or in something else. For the perfection of other beings is also agreeable, such as understanding, courage, and especially beauty in another human beings, or in an animal or even in a lifeless creation, a painting or a work of craftsmanship, as well. For the image of such perfection in others, impressed upon us, causes some of this perfection to be implanted and aroused within ourselves. (On Wisdom: GP VII 86; L 425)

Leibniz's claim here that only 'some of the perfection' perceived is implanted in the perceiver should not be read as endorsing the notion that some monads do not perceive the whole universe. Leibniz is clear that monads always perceive the perfect whole. ${ }^{19}$ Rather, the degree of perfection in the perceiver is proportional to the degree of distinctness of the monad's perceptions. Given that a monad's internal qualities are its perceptions and appetitions (the forces that move the monad from one perception onto the next in the sequence), and given that the perceptions can only be described in terms of their representational content together with the degree of confusion or distinctness of the representation, within the context of Leibniz's philosophical system, it makes sense to regard representations of external perfections as internal perfections of the mind, with the amount of the perfection 'implanted and aroused' in Nature and Grace, §§ 12-13: GP VI 603-604; M 275). 
this way dependent upon how distinctly the external perfection is perceived. Consequently, although all monads are beautiful insofar as their perceptions echo internally the full range of variety and order of the external world, they are not all beautiful to the same degree, for the more distinctly the external perfection is perceived, the more perfect and beautiful is the perceiver.

Such qualitative differences in the degrees of perceptual distinctness give each monad its unique perspective on the world. This in turn allows each to make its own distinctive contribution to the harmonious variety and order of the world as a whole. The magnificent beauty of the world itself is manifested in the infinity of distinct and unique individuals as well as the order and harmony that comes from the fact that their perceptions all represent the same world, a world in which each finite individual mirrors not only the world, but also its Divine Creator: ${ }^{20}$

every substance is like a complete world and like a mirror of God or of the whole universe, which each one expresses in its own way, somewhat as the same city is variously represented depending upon the different positions from which it is viewed. Thus the universe is in some way multiplied as many times as there are substances, and the glory of God is likewise multiplied by as many entirely different representations of his work.

(Discourse on Metaphysics, §9: GP IV 434; AG 42)

20 The Leibnizian universe actually contains multiple harmonic orders: of bodies, of perceiving monads, and of souls and bodies united. Described more abstractly, these harmonies are systems of efficient causes and of final causes operating in parallel, each so finely tuned that, whatever is happening in the one corresponds exactly to what is happening in the other, in the manner of a mathematical bijective function. A further harmonic ordering, which perhaps need not concern us here, is the harmony between the kingdoms of nature and grace, where the kingdom of grace is the moral kingdom of God comprising all rational minds and spirits. For further details, see Phemister 2003 and Strickland 2016. 
Variations in the degrees of perfection are essential if monads are to be distinguished both from each other and from God. On the other hand, of course, this means that all finite created beings contain some imperfections. Whether these imperfections are mere absences of perfection or actual imperfections, it is clear that in mirroring each other, each monad must represent not only the others' perfections, but also their imperfections. Just as the images of the perfections of others are 'implanted and aroused' in the perceivers, so too must be the images of others' imperfections and the question must be asked: Do these imperfections and their images pose a threat to the idea that Leibniz advances a positive aesthetics in respect of the natural world?

Superficially, this might appear to be the case, but Leibniz himself argues that any imperfections, taken in the context of the whole, benefit rather than detract from the beauty of the world. Obviously some imperfections are required in order to increase nature's variety and, in the case of less than fully distinct perceptions, these can be accommodated without any diminution of the order among things: order is retained because all monads perceive the same world in its entirety; maximum variety is introduced because the differing degrees of distinctness of monads' perceptions ensure that the world is perceived from all possible perspectives. In this way, therefore, what appears in a limited context an imperfection is, when considered in its wider context, a valued part of the whole. By way of illustration, Leibniz draws upon the visual and aural arts:

Look at a very beautiful picture, and cover up except for some small part. What will it look like but some confused combination of colors, without delight, without art; indeed the more we examine it the more it will look that way. But as soon as the covering is removed, and you see the whole surface from an appropriate place, you will understand that what 
looked like accidental splotches on the canvas were made with consummate skill by the creator of the work. What the eyes discover in the painting, the ears discover in music. Indeed, the most distinguished masters of composition quite often mix dissonances with consonances in order to arouse the listener, and pierce him, as it were, so that, anxious about what is to happen, the listener might feel all the more pleasure when order is soon restored. (On the Ultimate Origination of Things: GP VII 306; AG 153) ${ }^{21}$

All created monads, insofar as they possess varying degrees of power, of knowledge or perception, and appetites or drive towards the good, are created in the image of a God conceived as omnipotent, omniscient and universally benevolent (Phemister 2016: chapter 6). Leibniz's God is a fully rational God and in this respect, rational minds and spirits bear the closest resemblance to their Creator. The principles of reason are the same in God as they are in finite minds. The intelligible order and harmony that pleases God is the same order and harmony by which the world becomes intelligible to finite minds and that is pleasing to them when they contemplate it. In short, the principles of reason that govern human thought are believed by the Leibnizian theist to be exactly the same rational principles that characterise God's omniscience.

It is thus through theological belief in the existence of a rational and good God that we can be convinced that the order and harmony the natural sciences find in our multi-faceted world are not illusory, but that the world itself in all its parts is in principle intelligible. In the absence of a theological belief in divine rationality, the sciences cannot guarantee that the world itself conforms throughout to our intelligible reconstruction of it. Nor can they guarantee that our rational understanding of the world is an accurate representation of 21 See also Leibniz to Sophie Charlotte, 9/19 May 1697: GP VII 545; LTS 160. 
the world as it really is in itself. The natural sciences on their own cannot provide a sure guarantee that the principles of harmony and order that signal intelligibility to the human mind are applicable throughout all nature. The natural sciences have not, and perhaps never will, achieve complete understanding of the natural world. The major part remains hidden from view. Without the theological grounding jettisoned by Carlson, it remains a real possibility that natural scientific explanations indicate more about the nature of the human mind and its need to find order and harmony in what is essentially a chaotic system than it does about the actual nature of the world itself. For Leibniz's rational theist, however, the intelligibility of scientific explanation is justified by the theological belief in the rationality and intelligibility of the creator. To the Leibnizian believer, the order and harmony already discovered through the sciences is representative of a beautiful order and harmony throughout a world freely chosen by a rational God who finds goodness, perfection and intelligible beauty in the maximisation of variety within unifying orderliness.

\section{Conclusion}

In this paper, we have argued for a reading of Leibniz's aesthetics as an early example of a positive aesthetics of nature. In satisfying this modest aim we have also tried to show that Leibniz's version of positive aesthetics is plausible, not just in itself but also vis-a-vis modern versions of the doctrine, in particular that developed and endorsed by Allen Carlson. We have noted already Malcolm Budd's concern that the doctrine of positive aesthetics is often vague or imprecise, inasmuch as formulations of the doctrine typically leave it unclear whether it applies to nature as whole, or the biosphere, ecosystems, species, individual (natural) things, or individual (natural) events (Budd 2002: 97). As we have already shown, while the charge of vagueness or imprecision does apply to Carlson's 
version of the doctrine, it does not to Leibniz's; for whereas Carlson is not clear as to what exactly he thinks the doctrine applies, Leibniz explicitly tells us that the whole is beautiful, as is each and every component of that whole, that is, each monad together with its organic body, as well as every aggregate body composed of these. In this way, Leibniz's positive aesthetics is all-encompassing, and this too makes it more attractive than Carlson's: for when faced with the objection that the natural world contains instances of ugliness, e.g. in malformed living things, Carlson swiftly concedes the point, thus making his version of positive aesthetics limited in scope. Leibniz's version, meanwhile, recognizes no exceptions whatsoever; he tells us that if we think we have found an example of natural ugliness or disorder, it is because we are not considering it aright. Thus to two of the most common objections to positive aesthetics, Leibniz's version of the doctrine offers the more satisfying response. Leibniz's version of positive aesthetics has a further advantage over Carlson's on account of its justification. While Leibniz, like Carlson, offered a justification of the doctrine based on the natural sciences, Leibniz realised that this alone was not sufficient. He saw that it needs to be supplemented by a rational theology that validates scientific method and that also brings into focus the contributions of the monads to the overall beauty of the created world. To be fair, a theological justification alone is also not sufficient. Although in this paper we have highlighted the deficiencies of the sciences in this regard, it is equally the case that without the natural sciences, we would be ignorant of the 'wonders of nature' that, for Leibniz, not only evidence the beauty of nature, but point further to the beauty of their creator and that underpin the beauty of all who perceive them. Together, however, the natural sciences and theology offer the strongest justification of a positive aesthetics of nature. 


\section{BIBLIOGRAPHY}

A = Leibniz, Gottfried Wilhelm (1923-). Sämtliche Schriften und Briefe. Edited by Berlin-Brandenburgische Akademie der Wissenschaften (Berlin: Akademie Verlag). Multiple volumes in 8 series, cited by series (reihe) and volume (band).

AG = Leibniz, Gottfried Wilhelm (1989). G. W. Leibniz: Philosophical Essays. Edited and Translated by Roger Ariew and Daniel Garber (Indianapolis and Cambridge: Hackett Publishing Company).

Barnes, Jonathan, ed and tr. (1984). The Complete Works of Aristotle, 2 vols. (Princeton: Princeton University Press).

Beiser, Frederick C. (2009). Diotima's Children: German Aesthetic Rationalism from Leibniz to Lessing (Oxford: Oxford University Press).

Berkeley, George (2008). Philosophical Writings. Edited by Desmond M. Clarke (Cambridge: Cambridge University Press).

Borruso, Silvano, tr. (2007). St. Augustine: On Order (De Ordine) (South Bend, Indiana: St. Augustine's Press).

Brady, Emily (2010). 'Ugliness and nature', Enrahonar, 45, 27-40.

Budd, Malcolm (2002). The Aesthetic Appreciation of Nature (Oxford: Clarendon Press).

Burnet, Thomas (1684). The Sacred Theory of the Earth (London). 
Carlson, Allen (1984). 'Nature and Positive Aesthetics', Environmental Ethics, 6:1, 5-34.

Carlson, Allen (2000). Aesthetics and the Environment: The appreciation of nature, art and architecture (London: Routledge).

Carlson, Allen (2002). 'Hargrove, positive aesthetics, and indifferent creativity', Philosophy and Geography, 5:2, 224-34.

Cassirer, Ernst (2009 [1951]). The Philosophy of the Enlightenment. Translated by Fritz C. A. Koelln and James P. Pettegrove (Princeton: Princeton University Press).

Fisher, John Andrew (2001). 'Aesthetics'. In A Companion to Environmental Philosophy. Edited by Dale Jamieson (Oxford: Blackwell), 264-276.

GP = Leibniz, Gottfried Wilhelm (1875-90). Die Philosophischen Schriften von Gottfried Wilhelm Leibniz. Edited by C. I. Gerhardt, 7 vols. (Berlin: Weidman). Reprint, Hildesheim: Olms, 1965.

Gr = Leibniz, Gottfried Wilhelm (1948). Textes inédits. Edited by Gaston Grua. 2 vols. (Paris: Presses Universitaires de France).

Guyer, Paul (2014). A History of Modern Aesthetics. 3 vols. (Cambridge: Cambridge University Press).

$\mathrm{L}=$ Leibniz, Gottfried Wilhelm (1969). Philosophical Papers and Letters. Edited and translated by Leroy E. Loemker. $2^{\text {nd }}$ edition (Dordrecht, Holland: D. Reidel Publishing Company). 
LGR = Leibniz, Gottfried Wilhelm (2016). Leibniz on God and Religion. Edited and translated by Lloyd Strickland (London: Bloomsbury).

Leibniz, Gottfried Wilhelm (1985). Theodicy: Essays on the Goodness of God, the Freedom of Man, and the Origin of Evil. Translated by E. M. Huggard (La Salle, Illinois: Open Court).

LTS = Leibniz, Gottfried Wilhelm (2011). Leibniz and the Two Sophies: The Philosophical Correspondence. Edited and translated by Lloyd Strickland (Toronto: Centre for Reformation and Renaissance Studies).

$M=$ Leibniz, Gottfried Wilhelm (2014). Leibniz's 'Monadology': A New Translation and Guide. Edited and translated by Lloyd Strickland (Edinburgh: Edinburgh University Press).

Moltmann, Jürgen (1985). God in Creation: An Ecological Doctrine of Creation. The Gifford Lectures, 1984-1985. Translated by Margaret Kohl (London: SCM Press).

NE = Leibniz, Gottfried Wilhelm (1982, repr. 1985). New Essays on Human Understanding. Edited and translated by Peter Remnant and Jonathan Bennett (Cambridge: Cambridge University Press).

Parsons, Glenn and Carlson, Allen (2008). Functional Beauty. (Oxford: Oxford University Press).

Phemister, Pauline (2003). 'Exploring Leibniz's Kingdoms: A

Philosophical Analysis of Nature and Grace', Ecotheology, 7:2, 126145. 
Phemister, Pauline (2005). Leibniz and the Natural World: Activity, Passivity and Corporeal Substances in Leibniz's Philosophy (Dordrecht: Springer).

Phemister, Pauline (2015). 'Seeds and Souls'. In Leibniz's metaphysics and adoption of substantial forms. Edited by Adrian Nita (Dordrecht: Springer), 125-141.

Phemister, Pauline (2016). Leibniz and the Environment (London: Routledge).

Ray, John (1691). The Wisdom of God manifested in the Works of Creation (London).

SLT = Leibniz, Gottfried Wilhelm (2006). The Shorter Leibniz Texts: A Collection of New Translations. Edited and translated by Lloyd Strickland (London: Continuum).

Strickland, Lloyd (2016). 'Leibniz's harmony between the kingdoms of nature and grace'. Archiv fur Geschichte der Philosophie. 